\title{
Transmisión hereditaria a través de la mujer en la Grecia clásica
}

\author{
JESÚS CEPEDA *
}

\begin{abstract}
RESUMEN
ABSTRACT

La mujer en Grecia durante el periodo

The greek woman during the classic period, she had legal and economic rights that she was always under a legales y económicos que la colocaban bajo la tutela de un hombre a lo largo de toda su vida, bien fuera su padre o posteriormente su marido, quién administrará en su nombre su dinero y bienes. Se analizan las distinas disposiciones legales de la mujer en Atenas, en claro contraste con las de la mujer en Esparta o en guardian during all her life, firstly her father and secondly under her husband, that he will manage money and properties in her name. In this study the different legal rights are analyzed, in sharp difference with the legal rights of the Spartan woman and even the woman in Gortina.
\end{abstract}

Gortina.

El estudio de la mujer en Grecia durante la época clásica, cualquiera que sea el ámbito que abordemos, resulta del todo paradójico. Por un lado, no existe otra región del Mundo Antiguo, donde la mujer haya sido tan estudiada, ya sea en el terreno literario o en el artístico, y con más interés si cabe en la tragedia, escultura y pintura que en la Atenas del periodo clásico.

Existe por tanto una dilatada documentación que nos permite reconstruir, aunque con gran número de lagunas, la posición de la mujer tanto en

* Departamento de Prehistoria e Historia Antigua. UNED. 
aspectos políticos, legales como económicos, dentro de la estructura de la sociedad Ateniense.

Sin embargo, lo realmente paradójico es que no disponemos de una sola evidencia que pueda sacar a la luz la verdadera voz de la mujer. En Medea de Euripides, escucharemos la voz apasionada de una mujer, pero no debemos olvidar que el que habla es Euripides. Sabemos por tanto lo que los hombres decían de las mujeres, y cual era la imagen que de ellas tenían, pero sabemos muy poco realmente de ellas. Es muy difícil encontrar una visión propia de una mujer que no tenga una concepción masculina.

Debemos estudiar las fuentes con gran precaución, sin llegar a pensar que descubriremos la verdad sobre las vidas de las mujeres, pero tampoco dejarnos llevar por un sentido fatalista y pensar que no nos ofrecen nada. Las mujeres griegas vivian bajo el mundo de reglas que habian instaurado los hombres. Inevitablemente un punto de vista de la mujer en la sociedad griega nos ha sido negado y la única verdad que tenemos sobre esa sociedad es una verdad masculina.

Afortunadamente para el tema que vamos a desarrollar a continuación, al tratarse de un asunto económico-legal, disponemos de la documentación necesaria para hacernos una idea de cuál era la situación legal en la que se encontraba la mujer ateniense en la época clásica, y descubriremos además, cómo no fue dicho modelo el único que se desarrolló en todos los rincones de Grecia, cómo podremos comprobar en los casos de Esparta y Gortina.

Debemos ser conscientes que el estudio tan solo abarca aquellas clases sociales de las que tenemos suficiente documentación para llegar a conclusiones válidas, y no podemos incluir casos como los de las esclavas, extranjeras o prostitutas con status económico propio. Tan solo mujeres griegas libres, y que en su gran mayoría pertenecen a la clase alta de la sociedad.

\section{DERECHOS POLITICOS}

Analicemos en un primer apartado, los derechos políticos que tenian las mujeres, antes de profundizar en los económicos o legales. Una mujer ateniense no podía votar en la Eklesía, ni tan si quiera podía acudir a sus reuniones, con lo que no tenía ni voz ni voto.

No podian ocupar cargos administrativos o ejecutivos, no podían formar parte de un jurado, ser miembros de los concilios, pronunciar discursos públicos, etc.; en resumidas cuentas, la mujer no tenia derechos políticos. En el sentido griego de la palabra no eran ni ciudadanos, pues eran con- 
siderados "astai" y no "politai", es decir gozaban de derechos religiosos, económicos y legales, pero no eran ciudadanos. Según la definición de Aristóteles eran "participantes de los honores del Estado". Eran personas que junto a los niños eran necesarios para la existencia de la polis, pero no eran ciudadanos (1).

Esta situación puede verse reflejada en el Lysistrata de Aristófanes:

"Aunque la democracia necesita de ellas, son excluidas de sus instituciones y aunque después del 451 se les asigna un importante papel en la transmisión de derechos de ciudadanía, ellas mismas no pueden disfrutar de muchos de los privilegios de ser ciudadano".

La democracia fue una invención del hombre para el hombre y sin la mujer, debido a que acentuó aún más la disparidad entre las vidas de los hombres y las mujeres. En 1982, Fox-Genovese resumia en tan solo unas frases la situación de aquél momento:

"Al menos tenemos la seguridad de que mientras los hombres estaban realizando proezas, construyendo instituciones, produciendo bienes y culturas. dirigiendo personas y generaimente todas esas actividades que nosotros llamamos historia, las mujeres indudablemente estaban haciendo algo. aunque solo fuera criar más hombres que continuaran haciendo historia y más mujeres para soportarlos".

Sin embargo las mujeres eran fundamentales en la organización y estructura de la polis, incluso si su papel era meramente pasivo. Como analizaremos más adelante, los derechos económicos y hereditarios fueron transmitidos a través de la mujer tanto como a través del hombre.

\section{DERECHOS ECONÓMICOS}

Una mujer no era considerada legalmente competente, autónoma o responsable de sus propias acciones o capaz de determinar sus propios intereses. En palabras de Harrison (2):

"No hay duda de que la mujer griega permaneció bajo algún tipo de tutelaje durante su vida entera. No podía realizar el más minimo contrato, no podia casarse por su cuenta y no podia llevar ella misma un caso ante la corte. En todas estas relaciones, dependia de su kirios y asi fue durante su vida entera"

Una mujer no podia entrar en una transacción económica más allá del valor de un medimno de cebada, medida que podría alimentar a una 
familia durante cinco o seis días (3). Era una marca de dominio del hombre.

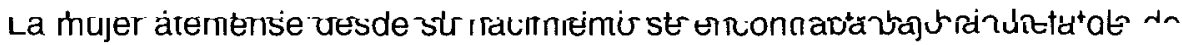
algún hombre, bien fuese su padre, un hermano o posteriormente su marido. Esta tutela incluía la administración del dinero o las propiedades a las que tuviera derecho, por lo que la mujer tan solo podía disponer de sus objetos personales, regalos y algo de dinero para los asuntos domésticos.

\section{FAMILIA Y MATRIMONIO}

El papel doméstico que ya tenía asignada la mujer en la Grecia Arcaica, cambió muy poco con la llegada de la época clásica, debido a que seguian prevaleciendo las actividades domésticas y estaban muy poco incorporadas a actividades fuera de casa.

"Las diferencias de la época arcaica a la clásica, política y culturalmente ha debido incidir más en los hombres que en las mujeres.»(4)

La mujer desde su nacimiento, estaba bajo la tutela del kirios, que normalmente era su padre, salvo en los casos en que la muerte de éste, llevaba a que estuviera bajo la tutela de alguno de sus hermanos, convirtiéndose asi en su nuevo kirios, quién se encargaría llegado el momento de acordar su matrimonio.

El kirios de una familia tenía autoridad sobre ellos y también responsabilidad sobre su mantenimiento. El kirios de un niño, normalmente era su padre, y cuando éste moria pasaba a serlo un hermano mayor o el abuelo por parte paterna.

En Atenas no era normal que una mujer fuera independiente, es decir que no estuviera bajo la tutela de su kirios, excepto las mujeres extranjeras (metecas), que podía ser que no tuviesen parientes en Atenas y ser ellas su propio kirios. A pesar de ello, debería tener su propio representante ante las instituciones (prostatai), quien podría hablar por ella en asuntos legales.

Las leyes atenienses reconocían que la sociedad no se componía solamente de individuos sino también de oikos o núcleo familiar, que incluia las tierras que mantenian a dicha familia, además de la casa y todo ellos en manos de kirios. El oikos tenía sus ceremonias religiosas, incluyendo ritos por los antepasados, etc.

Sirvientes, concubinas y niños ilegítimos no eran parte del oikos, aunque vivieran en la misma casa. El oikos lo integraban por tanto el kirios, su 
mujer, los hijos legítimos, la madre del kirios si era viuda, sus hermanas solteras y otros parientes. Si las hijas o hermanas se casaban, abandona-

ban el oikos_v_nasaban al oikos del marido. Si lps_aue se casaban eran los hijos varones, traían al oikos a sus mujeres y también serían parte de éste los hijos y nietos.

Un hombre podía ser kirios de su oikos, pero no lo era de su hijo, cuando éste ya se había casado ni de la esposa de éste ni de los consiguientes hijos de ambos, pues en este caso, el propio hijo sería el kirios de su esposa e hijos.

Será precisamente ésta una de las causas, en las que la mujer adquiera un papel crucial, para evitar la desaparición de un oikos, ante la ausencia de herederos varones, convirtiéndose entonces en una epiclera como analizaremos más tarde.

El matrimonio estaba envuelto en una transferencia de propiedades y durante el periodo homérico, el elemento más importante de la transacción era el mantenimiento de la novia o hedna, que consistía en regalos que llevaba el novio al padre de la novia cuando un matrimonio se acordaba.

Existía a veces competencia por la mano de una novia y los regalos se intentaban superar unos a otros.

La atracción física no era motivo de matrimonio debido a las pocas salidas que realizaban las jóvenes fuera del lugar donde residian. Periandro, tirano de Corinto en el VII-VI a.C., se enamoró de su futura esposa Melisa, cuando la vio en un campo, vistiendo una simple túnica y llevando vino a los trabajadores. Sin embargo los sentimientos de Melisa no se tomaron en cuenta y el matrimonio fracasó. Finalmente el marido la mató en un ataque de celos y una vez muerta la violó. (5)

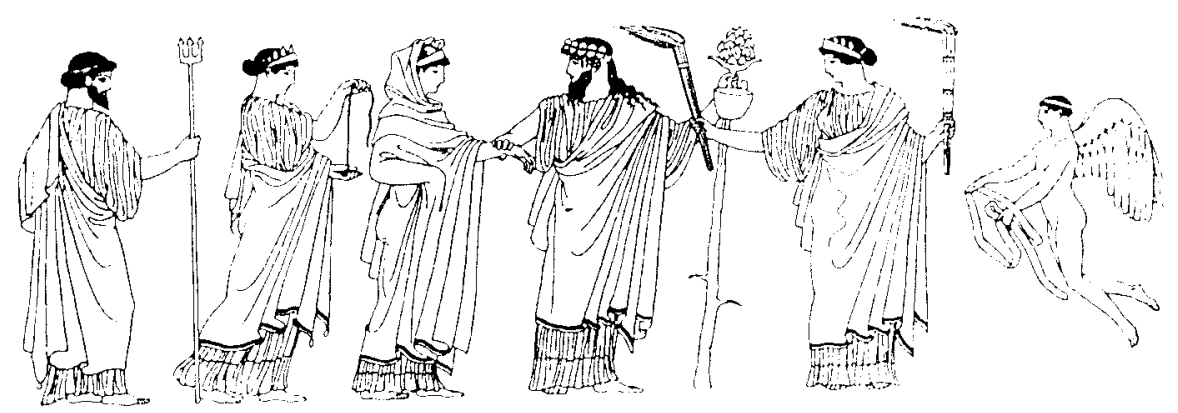

Fig. 1. Krátera sigio v a. C. Reading Art Museum. Representación de una boda con personajes mitológicos. Nótese la manera en que el novio coge a la novia, sujetándola de la muñeca y no de la mano. 
Al final de la época arcaica se produjo un importante cambio a la hora de la transferencia de la propiedad con el matrimonio. Los regalos del novio al padre de la novia, eran cada vez más insuficientes, mientras que la dote (propiedad que el padre daba a la novia cuando se casaba) era muy sustanciosa. Dar una dote a una hija se convirtió en algo esencial para acordar un matrimonio durante el periodo clásico, y distinguió a los griegos de otras gentes contemporáneas, distribuidas por el continente europeo, tales como los celtas y germanos, quienes pagaban por sus esposas.

Esta evolución corrió pareja a la evolución de la polis para establecer unas diferencias entre funciones de los distintos sexos. Sin embargo no es fácil establecer por qué predominó la dote sobre otras posibilidades. Además esta dote toma en el periodo clásico forma de dinero, joyas u objetos de alto valor económico. De esta manera un padre tenía la certeza de que sus propiedades permanecerían intactas al permanecer en manos de sus hijos. (6)

De acuerdo con Hesiodo, los hombres se casaban para tener hijos que cuidaran de ellos en su vejez y heredaran sus propiedades cuando ellos murieran. De esta manera se aseguraban que sus tierras no pasaran a parientes lejanos.

En los poemas de Homero, la mujer es presentada con gran respeto, mientras que en los de Hesiodo, la misoginia es evidente. Una de las razones puede ser que mientras Homero habla de los grupos acomodados de la sociedad, Hesiodo lo hace del pueblo llano, donde la mujer aparece como simple reproductora de herederos que se encargasen de administrar las propiedades y no cayeran en manos de parientes lejanos.

A principios del siglo $\mathrm{VI}$ aC, Solón introdujo leyes que tenían efectos represivos sobre las mujeres, y puso límites a sus ajuares y a sus apariciones en funerales, incluso medidas para controlar su comportamiento sexual y todo ello con vistas a la supervivencia del oikos o unidad familiar. Así la mujer se veía sometida a una doble subordinación, la de la familia y la del Estado.

En la Grecia Clásica, las familias numerosas eran excepcionales, debido a que de esta manera se aseguraba la cohesión de las propiedades familiares que serian divididas en un menor número de proporciones. El coste de las dotes también desanimaría a tener hijas. Según el estudio realizado por Sarah Pomeroy en los años 70 , una vez que se consideraba que el número de hijos era el adecuado, el matrimonio ya no dormía en la misma cama, siendo ocupada eventualmente por alguna esclava o concubina. 


\section{LA DOTE}

Si un hombre quería casarse, debía llegar a un acuerdo con el padre de la novia, acuerdo que recibia el nombre de engye. No era necesario que la novia estuviera presente, ni tan siquiera que consintiera o que se enterara de que se había casado. En este acto existía un acuerdo económico, por el que el padre de la novia hacía entrega por lo general de una cantidad de dinero, objetos valiosos, etc. al novio en concepto de dote. Tenemos documentos que nos muestran cómo se desarrollaba la engye (7):

-Pataecus: Yo te doy esta mujer para procreación de hijos legítimos.

-Polemon: Yo acepto.

-Pataecus: $Y$ tres talentos como dote.

-Polemon: Así todo es correcto.

El segundo acto del matrimonio se denominaba gamos y se realizaba cuando la novia se trasladaba a la casa del marido, en el momento en que lo creyeran conveniente ambas partes.

Una mujer no podía casarse legalmente con un ascendiente o descendiente (abuelo, padre, hijo, nieto, hermano o hermanastro de madre). Pero sí se podía casar con el hermanastro por parte de padre, con su hermano adoptivo, su tío, primo o parientes más distantes y por su puesto con un hombre que no fuera pariente (8).

Acordar un matrimonio es la principal misión de la familia en la que acaba de nacer una niña. En primer lugar esta responsabilidad recae en el cabeza de familia o kirios, que en caso de muerte pasa al hermano y si no al abuelo paterno. La principal responsabilidad de acordar la boda es dotar a la novia de una dote y en función de la misma quedará establecido el estatus de la novia en su nueva familia.

La cantidad económica que se otorga a las dotes varía de unos casos a otros, según la capacidad económica del oikos. El caso que hemos señalado anteriormente pertenece a una familia de clase alta, pues tres talentos era una cantidad importante. Por lo general la dote variaba entre las 10 y 15 minas, mientras que las propiedades adjudicadas en la misma solían ser escasas, debido principalmente a que sería más fácil la administración de dinero que la de propiedades.

La principal intención de una buena dote era atraer a un buen esposo. Una mujer sin dote corría el riesgo de quedarse soltera toda la vida. Por otro lado una dote muy elevada podía atraer oportunistas sin escrúpulos. 
Es muy dudoso aseverar que las jóvenes atenienses crecieron sin apenas salir a la calle, pero no es menos cierto que las chicas de buena familia no podian tratar libremente con el hombre, por lo que era imposible atraer un esposo por méritos propios.

El novio al aceptar la dote, adquiría la responsabilidad de mantener a la esposa mientras durase el matrimonio. En caso de divorcio, el kirios de la novia podía demandar al esposo la devolución de la dote, con un interés del $18 \%$. (9)

La dote no pertenecía en un sentido estrictamente legal a la mujer. Ella no podía disponer de ella, sino que era el esposo el que podría hacerlo, sin olvidar la obligatoriedad de devolver dicha dote en caso de divorcio al kirios original de la mujer.

Encontramos en casos como el de Menandro (10), un anciano al que le urge obtener el divorcio de su hija antes de que se gaste el yerno la dote. Finalmente fue confiscada por los acreedores del esposo. La mujer solo podía reclamar en caso de divorcio, muerte de algún hijo o confiscación de las propiedades. Es muy curioso observar cómo estas reclamaciones se realizaban en nombre de la mujer, como si ella misma pudiera disponer de la misma. Suplicaba a los acreedores que no se llevaran los muebles pues eran parte de la dote (11):

— No toquéis los muebles, chilló ella, y no cojáis nada de lo mío"

Los autores antiguos advierten de los peligros que conlleva casarse con una dote superior a las posibilidades del esposo:

- Menandro (12): "Cuando un hombre pobre elige casarse y acepta la dote que trae la novia, él se está entregando y no tomándola a ella".

-Plutarco (13): "Aquellos que se casan con mujeres por encima de sus posibilidades, se convierten en esclavos de la dote y no en esposos".

-Eurípides (14): “Incluso aunque libre, él es un esclavo de la cama de matrimonio, habiendo vendido su cuerpo por un dote».

Encontramos otros fragmentos interesantes como el Dyscolus, donde Gorgias duda acerca del matrimonio:

-Gorgias: No me parece agradable para mí vivir con el esfuerzo de otra gente. Prefiero ahorrar mi propio dinero.

-Sóstrato: Estás hablando tonterías. ¿No crees que sales ganando con el acuerdo?

-Gorgias: Creo que soy merecedor de ella, pero no creo que merezca la pena para un hombre con tan poco, tomar tanto. 
Una vez casado, el esposo podía encontrar fácilmente excusas para divorciarse si tenía problemas para mantener a su esposa como su dote exigía.

A una esposa se le exigía que fuera sexualmente fiel, pero a un esposo no. Se podía solicitar el divorcio en el caso en que el esposo detectara adulterio (15) y el seductor podía sufrir un severo castigo. Es interesante observar cómo la pena por violación era tan solo económica, fijada por Solón en 100 dracmas, mientras que la pena por seducción a una esposa era mucho más severa. El marido ofendido podía incluso llegar a matar al seductor, aunque lo más usual sería un castigo corporal, siendo el preferido el de "presionar rábanos contra su ano y cortarle el pelo púbico (16)".

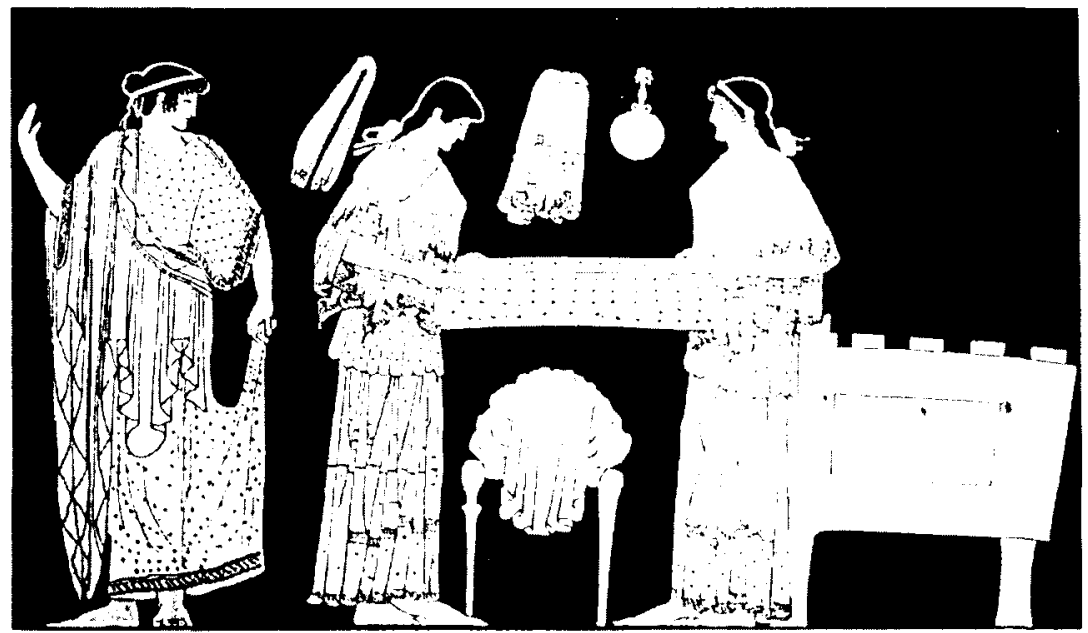

Fig. 2. Now-lost stamnos. Copenhage Museum. Pequeñas cajas y arcones eran de uso exclusivo femenino y en sus laterales solian representarse escenas domésticas. En este caso dos mujeres sostienen entre sus manos un trozo de tela, mientras a la izquierda otra mujer observa la escena. A la derecha podermos observar un arcón, probablemente para guardar los vestidos y en la pared colgado un espejo.

El divorcio era un proceso muy simple, y consistía en que el esposo expulsaba de su casa a la adultera y así terminaba el matrimonio, sin mayor formalidad.

Si era la mujer la que quería divorciarse, el proceso era más complejo. No consistía ahora en dejarle, sino que debía notificarlo al arconte. Algunos investigadores sostienen que era un puro trámite, y que la esposa se divorciaba fácilmente, pero parece más probable que el arconte facilitaba la 
intervención del esposo para poder hacer volver a la esposa a la casa conyugal. Ningún arconte, según Plutarco (17), aceptaría el divorcio si el marido quiere que la esposa vuelva, por lo que es muy difícil que una mujer consiguiera el divorcio sin el consentimiento del esposo.

Algunas veces el divorcio podía ser solicitado por los familiares de la novia, quienes prefieren un nuevo matrimonio más ventajoso para ellos. Encontramos un texto de un autor anónimo del siglo Iv a.C. (18), en donde una mujer suplica a su padre que no la separe de su marido para casarla de nuevo:

— «Si mi marido me ha ofendido, deberia haberlo notado. Pero si no sé nada al respecto, quizás soy estúpida, no podría negarlo. Aún así, padre, incluso si una mujer es una estúpida criatura para juzgar una serie de asuntos, al menos, cuando se trata de sus propios asuntos, quizás tengamos algo de razón. Explicadme lo que mi esposo ha hecho contra mi ...

$Y$ ahora, tu quieres darme en matrimonio a un hombre rico, para salvarme de mi vida de angustia. ¿Dónde está el dinero, padre, que pudiera darme más felicidad que la que me da mi esposo? ¿sería justo que tomara parte en todas las cosas buenas que tiene mi esposo y no compartiera también su pobreza?. Decidme, si el hombre con el que queréis casarme, perdiera todo, ¿seguiriais queriendo casarme con otro ? ¿cuanto tiempo seguiréis padre tentando a la fortuna con respecto a mi vida, padre?

En el nombre de Hestia, no me robes el esposo con quién me casaste. Lo que te pido es justo y humano. Si rehúsas hacerlo estarás forzando tu voluntad y yo trataré de soportar mi destino con dignidad y evitar desgracia."

Si el matrimonio terminaba en divorcio, independientemente de la causa que lo motivara, la dote tenía que volver con la mujer a su primer kirios o heredero en caso del fallecimiento de éste. Esta sería una de las causas que no animarian a los esposos a aceptar el divorcio o a solicitarlo. Era una especie de seguro contra los divorcios. (19)

En el caso de que la mujer falleciera y no tuviera hijos, la dote podía igualmente volver al kirios original o su heredero, pero si existían hijos en el matrimonio, éstos heredaban la dote (20). Si era el esposo el que fallecía, la esposa tenía que volver a su oikos original. En este caso, el heredero del esposo tenía la obligación de devolver la dote (21).

Pero si la esposa tenía hijos o se encontraba embarazada en el momento de la muerte del esposo, podia permanecer con ellos en el oikos del esposo, siendo el nuevo kirios del oikos el administrador de la dote. Quizás esta fuese la única ocasión en que una mujer ateniense podía elegir por ella misma, entre volver a su oikos original o permanecer en el de su marido (22). 
Si el esposo no podía devolver la dote tras el divorcio de una vez, podía hacerlo en varias veces, pero pagando un 1,5\% mensual para el mantenimiento de la mujer. En el caso de no pagar, sería juzgado y condenado. Para evitar esta situación se solía poner una propiedad del esposo como garantía de la devolución si ésta fuera necesaria (apoitema).

Una mujer viuda o divorciada podía casarse de nuevo. En el caso de que hubiese vuelto a su oikos natal, su kirios podía darla a un nuevo marido por engye, como la primera vez, con dote incluida, una vez se hubiese recuperado la del anterior matrimonio. El propio marido, podía incluso en su lecho de muerte darla en matrimonio a otro esposo incluyendo la dote en el acuerdo (23).

En los estratos económicos más bajos, el valor económico de la dote disminuía. Eran las dotes de menos de 20 minas, llegando incluso a desaparecer la dote en las clases más bajas. Lo normal era que la dote estuviera en proporción con el poder económico del oikos, aunque tenemos casos como el de Cirón (24), un hombre cuya fortuna era importante y que tan solo dio a su hija una dote de 25 minas. Cuando murió su yerno, recuperó tal cantidad y volvió a casar a su hija con una nueva dote, esta vez de tan solo 10 minas.

Entre los grupos más pobres de la sociedad sin embargo era una cuestión de honor el ofrecer en la dote el máximo que pudieran dar. En Miconos, está epigráficamente comprobado (25) que las dotes estaban por encima de las posibilidades del oikos y es razonable pensar que esto también ocurría en Atenas entre las clases más pobres.

Los vestidos normalmente no eran parte de la dote y legalmente el esposo no tenía por qué devolverlos, pero en caso de divorcio, se solían devolver como gesto simbólico. Era más una cuestión de educación que no un tema legal. Aunque bien es cierto, que entre los más pobres se incluía todo, con tal de engrosar la dote, como hemos podido comprobar en las inscripciones de Miconos y darle una apariencia más atractiva.

La dote de una mujer ateniense no sólo dependía de la fortuna del padre, sino de la generosidad de parientes y amigos. Era considerado un gesto piadoso de los grupos sociales elevados, proveer dotes para los más pobres, de las que tenemos numerosos testimonios de tales benefactores (26).

Sería erróneo pensar que la mujer fue considerada en Atenas sólo como un medio para la alianza entre hombres o la transmisión de dinero o propiedades. Sin embargo, las mujeres fueron continuamente implicadas en un complejo juego de consolidación económica y dinámica de transacciones en 
las que ellas eran meros peones y esto debió de afectar en gran medida a su consideración social por parte de los hombres. Las mujeres eran el vínculo que unía a grupos de parientes y por las cuales eran transmitidos derechos religiosos y en cuyo nombre podian administrarse considerables fortunas.

\section{DERECHOS DE SUCESIÓN}

En la Grecia Arcaica, la herencia era patrilineal y cuando un hombre moría, sus tierras eran divididas en partes iguales entre los hijos varones que le sobrevivian. Una hija no heredaba, incluso cuando no había hermanos. Sin embargo a finales de la época Arcaica, parece que en muchas poleis, la propiedad comenzó a ser transmitida a través de las hijas en los casos en que no hubiera varones, asegurando así la continuidad del oikos.

En la Grecia Clásica, los derechos sobre la herencia eran determinados por proximidad familiar, pero la mujer no tenia derecho de herencia en presencia de un pariente cercano masculino en su misma condición. Una hija solo heredaba en ausencia de hijos, una hermana solo en la ausencia de hermanos, una tía solo en la ausencia de tíos. Pero no existen casos documentados en que a pesar de estas restricciones un tío por ejemplo tuviera mayores derechos de herencia que una hermana.

En Atenas, si un hombre moría sus propiedades pasaban en partes iguales a manos de los hijos varones, al no existir el derecho de primogenitura. Los hijos tomaban posesión sin ningún tipo de formalidad legal. En el caso de existir varios hijos varones, llegaban a un acuerdo sobre el reparto de las propiedades y en el caso de que tan solo hubiera dos hijos varones, uno de ellos dividía las propiedades en dos partes de igual valor y el otro elegía (27). Las hijas no heredaban propiedades, pero era obligatorio que les concertaran un matrimonio que incluyera una dote, que desde un punto de vista legal era parte del patrimonio del oikos, a la que cada mujer tiene derecho.

En la proximidad de la muerte, un hombre que no tenía descendientes directos y su oikos corría el riesgo de desaparecer, al caer sus propiedades en manos de un tío o un primo, que además no se encargarían de oficiar los ritos religiosos en honor del oikos y de la memoria de los antepasados, tenía la elección de adoptar un heredero varón que lo heredaría todo. No era común que se adoptara a una mujer, ya que ésta se convertiria en epiclera, y habría que esperar a que tuviera un hijo varón que lo heredaría todo. 


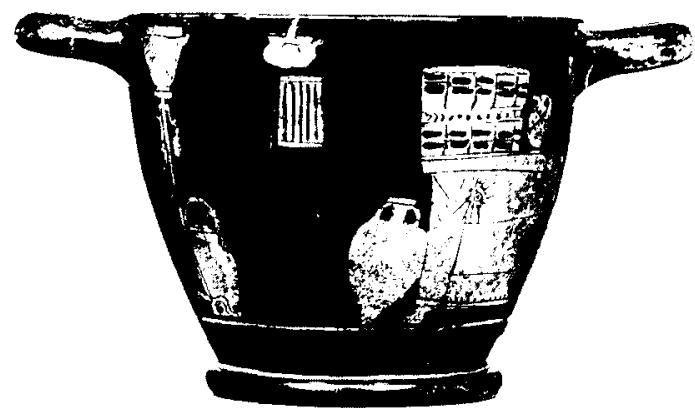

Figura 3. Skyphos. Cara B. Paul Getty Museum. Malibú. Representación de una estancia, donde no hay representada ninguna persona. Un ánfora de vino descansa sobre un arcón, sobre el que reposan una cesta de mimbre y una jarra. Otros recipientes y unas rejillas de cocina completan la escena.

Si el hombre ya tenía una hija y adoptaba un hijo, cabían dos soluciones:

La primera era que el adoptado y la hija se casaran y los descendientes heredarían las propiedades del abuelo.

Otra opción era que el adoptado concertaba el matrimonio de la hija con alguien y le hacía entrega de la mitad de las propiedades en concepto de dote.

El problema que podía surgir, era que los atenienses no tenían certificados de nacimiento o matrimonio y era por tanto difícil de demostrar ser el hijo de un segundo matrimonio o un pariente intermedio.

Harrison, en 1968 determinó que el orden de sucesión sería el siguiente:

1. Hijos del difunto (reparten las propiedades en partes iguales).

2. Hijas del difunto (convertidas en epicleras en ausencia de varones).

3. Hermanos del difunto y sus descendientes sin límite.

4. Hermanas del difunto y sus descendientes sin límite.

5. Tios por parte de padre, sus hijos y nietos.

6. Tías por parte de padre, sus hijos y nietos.

7. Hermanos del difunto por parte de la misma madre y sus descendientes sin límite.

8. Hermanas del difunto por parte de la misma madre y sus descendientes sin límite.

9. Tíos por parte de madre, sus hijos y nietos

10. Tias por parte de madre, sus hijos y nietos. 
Es fácil percibir el claro orden de sucesión patrilineal. Existen además un grupo de parientes del muerto, quienes en ausencia de herederos directos, tiene un orden establecido de herencia. Este grupo de parientes denominado anchistea, forma parte de un sistema legal en el que cada ateniense tiene un grupo de parientes bilateral, que podrían heredar en ausencia de herederos naturales o adoptados. Nuestras fuentes son Demóstenes e Isaios, pero desafortunadamente los textos no son muy fiables, encontrándonos con grandes lagunas en el primer caso y siendo el segundo una mera paráfrasis (28).

\section{EPICLERAS}

Cuando un hombre moria sin hijos varones, podia sin embargo dejar la herencia a una hija que se convertiría en epiclera y sería necesario que se casara y los descendientes de ese matrimonio heredarian las propiedades.

La palabra epiclerado proviene del vocablo Kléros que significa lote de tierra. Cuando una mujer heredaba estas propiedades, por su propia condición de mujer no podía ni ser propietaria ni administrar su patrimonio. Sin embargo ella transmitía los derechos de propiedad de estas tierras a sus hijos, de ahí la importancia de proporcionarla un marido dentro de su familia para que las propiedades permanecieran dentro de la misma (29).

A pesar de heredar la propiedad no podía disponer de ella y sólo guardarla hasta que su hijo fuese mayor de edad, con lo que daría lugar al surgimiento de competidores para casarse con la epiclera.

La ley establece que el pariente vivo más cercano al difunto, la pidiera en matrimonio y si había varios parientes de igual grado, por ejemplo varios tíos, el de más edad tenía preferencia.

En el caso de existir varias hijas, cada una hereda una parte igual de las propiedades y se convierte en una epiclera. Si la epiclera era pobre y no tenía pretendientes, la ley establece que para que no desaparezca el oikos, el pariente más cercano debe casarse con ella o darla en matrimonio incluyendo una dote. Estaba bien visto casar a una pobre epiclera y dotarle de dote(30). Tenemos documentado un caso muy peculiar (31) en el que podemos ver reflejada esta situación:

«Epilico, era mi tio, el hermano de mi madre. Murió en Sicilia sin herederos varones, pero dejando dos hijas, quienes debian pasar a Leagro y a mi. Los asuntos familiares no iban bien: las propiedades que dejo no llegaban a los dos talentos, mientras que las deudas ascendían a más de cinco talentos. Aún asi invité a Leagro a encontrarse conmigo en presencia de miembros de 
la familia y le dije que debíamos comportarnos como parientes más cercanos y que la situación requeria comportarse como los hombres honrados lo hacen. No es honrado por nuestra parte, preferir otra herencia de un hombre rico y dejar de lado a las hijas de Epílico. Después de todo si Epilico estuviera vivo, o hubiera dejado una gran suma de dinero a su muerte, nosotros esperariamos tener en matrimonio a las hijas al ser los parientes vivos más cercanos. Lo que habríamos hecho en ese caso es lo que debemos hacer ahora y lo haremos debido a nuestro buen carácter. Así pues pide en matrimonio a una de ellas y yo pediré a la otra."

El hecho de que se casase una epiclera para tener un heredero y perpetuar el oikos, puede apreciarse en la ley de Solón que indica que el marido debe tener con la epiclera al menos relaciones sexuales tres veces al mes y si él no pudiera, se permite a la epiclera casarse con otro pariente cercano (32). Esta disposición trataba de evitar que tíos muy ancianos de la epiclera la tomaran en matrimonio y no fueran capaces de darle algún heredero.

El arconte tenía la obligación de velar por los intereses de las epicleras así como de los huérfanos. La situación en que una epiclera es aún muy joven no está del todo claro y los investigadores se inclinan por el hecho

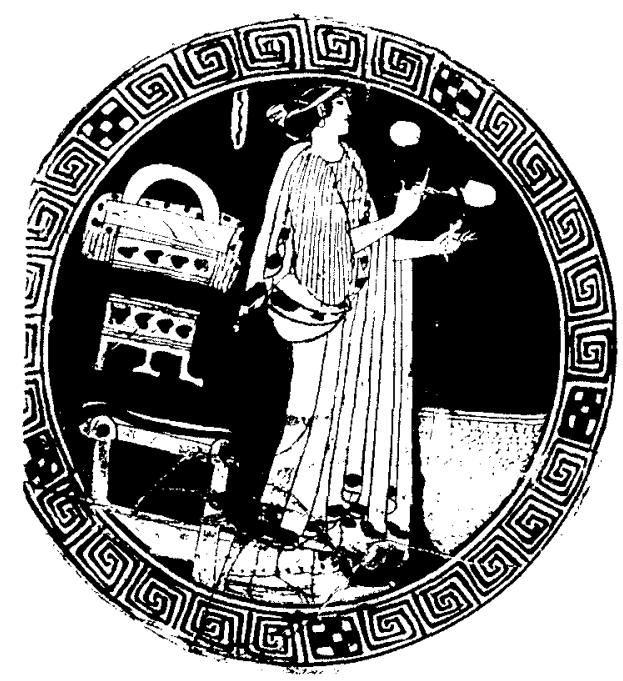

Figura 4. Interior de una taza. Siglo v a.C. Antikenmuseum und Glypothek. Munich. Una mujer en pie maneja un par de objetos de forma irregular, que bien podríta tratarse de ovillos de lana que almacena en la cesta que tiene debajo de base estrecha, llamada "Kalathos". Colgadas de la pared aparecen una cesta cilindrica con asa y más abajo un pequeño arcón. Es un reflejo más del mundo doméstico femenino. 
de que sea un pariente el elegido para cuidar de ella y administrar la propiedad como si fuera un huérfano y casarla al cumplir los 14 años.

Existía un serio problema cuando la hija del difunto se convierte en epiclera, estando ya casada y no tiene hijos. En ese caso el pariente más cercano puede reclamarla en matrimonio a pesar de estar ya casada. Es éste uno de los puntos que más atrae la atención de los investigadores actuales, debido a que dicho pariente podía forzar la disolución del matrimonio de la epiclera para obtener las propiedades del difunto. En cualquier caso, el pariente tan solo sería administrador de las propiedades hasta que un hijo de la epiclera alcanzara la mayoría de edad.

La esposa del fallecido no tenía derecho sobre la herencia y no podía convertirse por tanto en epiclera. Así mismo, los padres y abuelos del fallecido tampoco tenian derecho sobre la herencia, aunque este punto ha sido discutido por Harrison. Los bastardos tampoco tenian derecho sobre las propiedades, $y$ tenemos una ley del año $403 \mathrm{aC}$ que los excluye de las herencias y no los considera parientes (33).

La diferencia entre las propiedades de una epiclera y la dote de una doncella, era que en el caso de la primera el esposo podía ejercer un menor control sobre las propiedades que en el caso de la doncella recién casada, y por esta razón las fuentes nunca refieren las propiedades como de pertenencia al marido. Su posición era parecida a la del epitropos, que es el guardián de un huérfano, durante su minoría de edad.

Una rica epiclera era muy codiciada, y solía tener multitud de pretendientes. Encontramos casos como el de Protomaco que se divorció de su esposa para casarse con una de ellas y Timócrates parece haber hecho lo mismo. Existen multitud de documentos que atestiguan esta situación aunque la mayoría son apócrifos, pero dan prueba de lo importante que era la competición por la mano de una rica epiclera.

\section{VIDA SOCIAL DE LA MUJER ATENIENSE}

Las bodas y los funerales eran dos de las ocasiones en las que se podía ver un gran número de mujeres. La mayoria de los días la mujer ateniense los pasaba recluida en su casa, excepto aquellos grupos sociales en los que su deteriorada situación económica les hacia gozar de una mayor libertad, al tener que ir ellas mismas a los mercados, a recoger agua a las fuentes, etc.

La principal tarea de la mujer ateniense era por tanto enseñar a las esclavas en las tareas domésticas, cuidar y controlar todo el material de la 
casa y mantenerlo en orden y limpieza, administrar las dietas de los esclavos, etc.

Sin embargo, durante una boda o un funeral, la mujer se sentía protagonista, debido a que era uno de los pocos papeles que la sociedad ateniense les había asignado.

Las mujeres por tanto atendian festivales religiosos y ceremonias. Las "Tesmoforía" y las "Haloa" eran exclusivamente celebraciones femeninas. Además en las grandes ceremonias religiosas de Atenas, celebradas cada cuatro años como las "Panateneas", las mujeres iban en procesión como sacerdotisas y como portadoras de objetos rituales además de ser espectadoras en gran número.

Para una joven ateniense, ser elegida como "Kanefora" o portadora de objetos durante la procesión, era el más grande honor que podía esperar. Las mujeres eran también iniciadas en los misterios de culto, sobre lo que sabemos muy poco, pero en donde seguramente serian iniciadas por hombres.

En las bodas, el principal rito era el baño de la novia, para lo que había una procesión de mujeres, que transportaban el agua desde el manantial o «kallirhoe». La escena la encontramos representada en gran número de recipientes pintados, en donde una multitud portando antorchas y entre ellas un flautista que marcha en cabeza, seguida de una mujer que lleva el "loutroforos» o recipiente que contiene el agua para el baño ritual. La novia era rociada con ungüentos por sus ayudantes, obviamente también mujeres y durante la ceremonia, se sentaba al lado de la «nimfeutria», una mujer cuya tarea era guiar a la novia a lo largo de la ceremonia.

La novia era dirigida a la casa del novio en carroza, seguida por sus parientes y amigos, hombres y mujeres, cantando canciones de matrimonio y con la madre de la novia llevado la antorcha en la carroza (34).

Para las mujeres, una boda era probablemente uno de los acontecimientos sociales más importantes al que podían acudir y uno en los que no eran tan solo parte del público, sino parte activa del evento.

Debido principalmente a que la actividad social de la mujer ateniense durante el periodo clásico era tan reducida, también lo era la disposición económica que tenian, y los objetos que podían comprar, ya que recordemos les estaba prohibido por ley el llevar a cabo operaciones económicas de elevada cuantía. Por tanto debemos descartar en un principio que pudieran comprar propiedades, si exceptuamos los casos de Esparta y Gortina que analizaremos a continuación. 


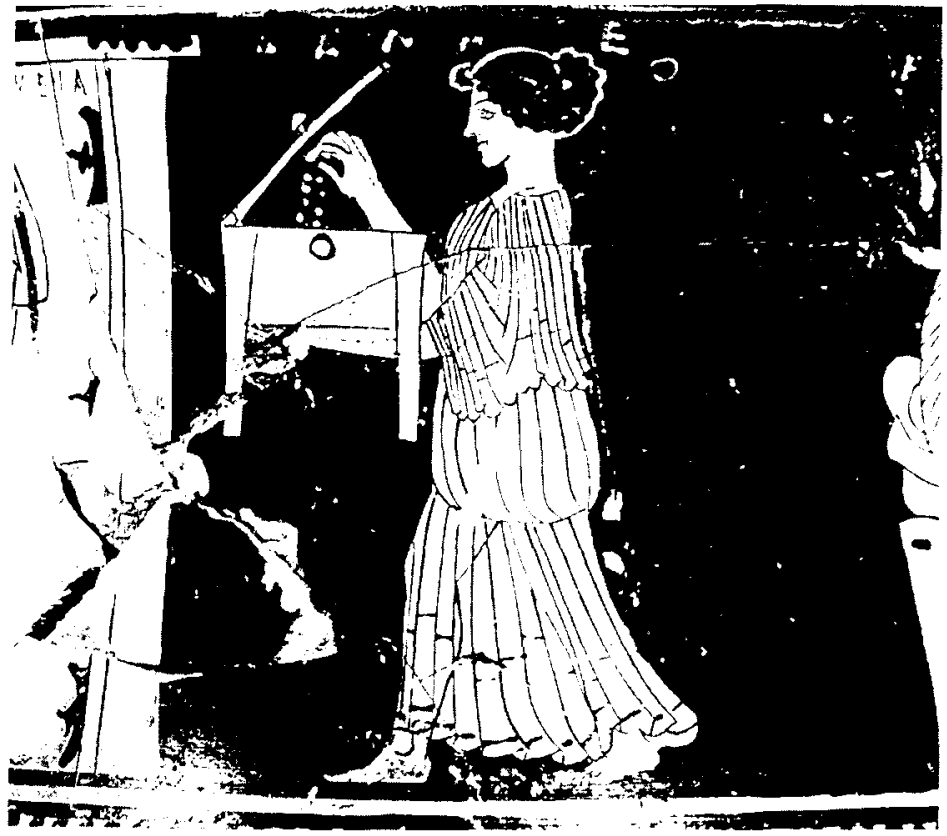

Fig. 5. Detail of Pyxis. British Museum. London. La mujer representada se dispone a adornarse con un collar que extrae de una caja donde guarda las joyas. Es muy común encontrar como motivo de representación en este tipo de objetos a una mujer vistiéndose o adornándose.

Tampoco podían intervenir en la compra y venta de esclavos, ya que en la mayoría de los casos los esclavos era manumitidos por el kirios y no por las esposas. A pesar de ello encontramos casos aislados como el de Nícaro, una mujer libre que pudo comprar y vender esclavos en Corinto a principios del siglo iv.

En lo que si tenemos certeza de que empleaban el dinero las mujeres era en las ofrendas a divinidades, encontrándonos un buen número de inscripciones conmemorando tales dedicaciones. A pesar de ello no son tan comunes como las de los hombres, donde podriamos obtener una proporción de una inscripción de mujer por cada cuatro de hombre.

No está muy claro si era necesario el consentimiento del kirios para realizar la ofrenda, aunque en algunos casos lleve la aprobación del mismo, como el de Epicteta, cuyo propósito fue establecer una fundación religiosa y encontramos la aprobación del kirios. Tenemos varias excepciones como las de Megaride y la de Calauria en el Peloponeso, pero no son suficiente para establecerlos como ejemplo para una regla general, y 
puede que la omisión de la aprobación del kirios se deba a la falta de un trozo de la inscripción o debido a las diferentes leyes que reinaban en cada una de las ciudades, en donde puede que no fuera necesario incluir el nombre del kirios, para realizar dicha ofrenda.

Recordemos que la Religión era la única institución griega donde el número de mujeres era realmente importante desde su jerarquía hasta su base. Que una mujer aparezca demasiado por el mercado, puede ser motivo de rebaja social, todo lo contrario de aparecer en los actos religiosos. Comprar, vender, y prestar eran operaciones en las que la mujer se veía muy limitada, porque era trabajo de su marido, sin embargo dedicación y sacrificios religiosos era una tarea de ambos.

No era necesario que la ofrenda realizada por una mujer a una divinidad se realizara con su propio dinero, y fuera empleado en su lugar el dinero del esposo, aunque en la inscripción solo apareciera como oferente el nombre de la mujer. Un hombre se pensaría dos veces el negarse a dar dinero a su mujer para realizar una ofrenda a una divinidad, aunque sería firme en rehusar emplear más dinero para nuevos vestidos para su mujer.

Las leyes atenienses no fijan quién debe tomar las decisiones monetarias dentro del matrimonio. Sí es cierto que establece cual de los dos puede realizar una transacción comercial, pero no quién puede manejar dinero dentro de la casa. No debemos sorprendernos si encontramos casos en los que el día a día no coincide con los términos legales establecidos. Mientras la cantidad de dinero manejada por las mujeres no afectara a las propiedades o negocios, les era permitido que manejasen cantidades de dinero más allá de su capacidad legal.

Cuando una mujer desobedece la ley, como en el caso de un adulterio, la ley le prohíbe llevar joyas o acudir a actos públicos, pero no recibe una sanción económica, pues según la ley no puede disponer más allá de una cantidad de dinero. Pueden rasgarle los vestidos, pueden arrancarle las joyas e incluso ser azotada, pero no imponerle una sanción económica. La ley ante un castigo, solo podía atacar su persona, pero no sus bienes personales.

Los vestidos, joyas, algún regalo para una amiga, etc. eran objetos que solía comprar la mujer ateniense. Artículos de cocina como las sartenes, vajillas, etc. son compartidos durante el matrimonio al igual que el mobiliario de la casa. Encontramos dos casos en los que se hace mención expresa de los muebles. El primero de ellos es cuando Sócrates se maravilla no solo de las ropas y los criados de Theodota, sino de la generosidad en el mobiliario. Otro caso es el de una mujer que reclama los muebles de la vivienda en el proceso de divorcio, alegando que eran parte de la dote. 


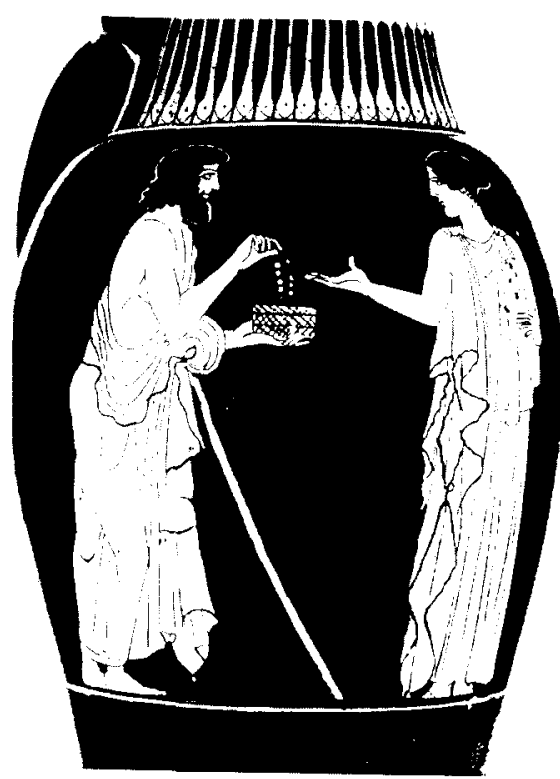

Fig. 6. Oinochoe. Musée du Louvre. Paris. En la iconografía ática es muy difícil encontrar una representación como ésta, en la que es el hombre el que sostiene un collar extraido de una pequeña caja. Una de las interpretaciones pone de manifiesto la posibilidad de que la

mujer esté siendo seducida por el hombre con un regalo como éste. En el centro de la composición podemos apreciar un destacado juego de manos alrededor de la caja de joyas.

Las joyas y los vestidos no podían estar incluidos en la dote, en cuyo caso no eran objeto de devolución en el proceso de divorcio, pero si se debía pagar por ellos. Una vez el matrimonio se ha disuelto, estaba bien visto, que el antiguo esposo accediera a entregar todos los vestidos, joyas, etc. a la mujer además de la dote, devolución ésta a la que sí estaba completamente obligado.

\section{MUJERES EN ESPARTA}

Esparta y Gortina son los únicos estados además de Atenas, de los que poseemos detallada información sobre el papel de la mujer. La mayoría de las evidencias provienen de fuentes clásicas y post-clásicas.

En ambos casos la situación social y legal de la mujer es diferente de la de Atenas. Ambas sin embargo, tienen inusuales instituciones sociales y no puede asumirse que los derechos que aqui poseen las mujeres fueran también los de las mujeres de otras partes de Grecia. 
Esparta ha tenido el único sistema social que ha sido capaz de levantar fuertes sentimientos, tanto de admiración como de antipatía. Lo mismo puede decirse de la opinión que se tiene sobre sus mujeres, desde la más profunda admiración hasta el horror por la libertad de que gozaban, muy difundido a través de Aristóteles. Lo que no debemos olvidar es que ninguna de las fuentes que nos han llegado pertenece a una mujer, y además ninguno de ellos era espartano, por lo que el material con que contamos se distancia doblemente del asunto a tratar.

La base de la sociedad espartana en palabras de Finley (35), era que la familia en Esparta quedaba minimizada a una unidad de afecto $o$ autoridad, y reemplazada por grupos de hombres. El estado espartano debia asegurar que los intereses de un hombre fueran canalizados hacia la vida pública, que en términos espartanos, significa vida militar.

A la edad de siete años un joven espartano era llevado fuera de su casa y hasta que cumplia los treinta viviria en barracas con otros hombres, a pesar de que se solía casar cuando llegaba a los veinte años. Una vez en la treintena, se le permitía residir con su esposa e hijos, pero incluso entonces, debería pasar la mayoria del tiempo fuera del ambiente doméstico, entregado a entrenamiento militar, campañas, caza, decisiones políticas, y comidas en común cada tarde. El resultado de esta sociedad es la caida del poder del padre de familia.

Esta disminución de poder en dicho personaje, trae como consecuencia el realce del papel de la madre, quien no tendrá problemas en el papel doméstico debido a las continuas ausencias del esposo. En la década de los setenta Redfield (36) aseguraba que la enorme separación de las esferas públicas y privadas, tanto en materia ideológica como material, habría asegurado el poder doméstico femenino, que era aceptado y posiblemente incluso oficialmente animado.

Hasta su partida hacia los barracones militares a los siete años, un niño pasaría la mayor parte del tiempo con su madre. Apenas habria tenido contacto con su padre y probablemente, para cuando su padre se instalase en casa, el niño ya se habría marchado al barracón.

Las niñas habrán estado bajo la madre hasta que se casen a los 18 años y éstas si habrán mantenido un contacto más directo con ellas. Estos lazos madre-hija, debieron reforzar el ambiente femenino para el que la sociedad espartan les habia reservado.

La mujer espartana no sólo debió de ocuparse de tareas domésticas, debido a que los esclavos aliviaban de las mismas. A diferencia de las mujeres atenienses, la casa no era el único sitio donde pasaban la mayor 
parte del tiempo. El entrenamiento físico era considerado tan importante en las mujeres como en los hombres y las chicas tomaban parte en competiciones de carreras o de fuerza (37), con carreras, lucha y lanzamiento de disco y jabalina. También aprendían a domar caballos, llevaban carros en las procesiones (38), etc. Es muy probable que muchas de las actividades atléticas femeninas fueran parte de los rituales que tenían lugar. Pausanias nos recuerda que en el santuario de Dionisio en Esparta, las mujeres llamadas hijas de Dionisio, lo utilizaban para realizar carreras.

Es posible que tanto hombres como mujeres realizaran pruebas atléticas en el mismo estadio a la vez. A veces desnudos, sin que esto fuera motivo de escándalo. Existen figurillas de bronce en donde uno de los pechos de una atleta queda al descubierto.

La belleza de la mujer espartana era muy conocida. En Lisistrata de Aristófanes podemos encontrar un diálogo muy significativo al respecto:

- Lisístrata: Bienvenida, Lámpido, mi querida amiga espartana. Querida, estás simplemente bella. Que complexión tan saludable, que vigor. Parece como si pudieras estrangular un toro.

-Lampito: Yo debería pensar también eso, por las dos diosas. Yo hago gimnasia, y saltos, golpeando mis talones hacia mi espalda.

-Lisístrata: $Y$ qué maravillosos pechos.

Según Platón (39) la educación de las jóvenes en Esparta, incluia el estudio de las artes además de pruebas atléticas. También coros de mujeres y canciones de nodrizas escritas por el poeta Alcman. En estos poemas, Alcman sugiere el estrecho contacto que existe en grupos de chicas por edades igual que en los de chicos, con relaciones homosexuales entre ellas y sus instructoras (40).

La mujer espartana se casaba relativamente tarde en comparación con su homónima ateniense, debido a que se consideraba que la mejor edad para concebir y criar a niños fuertes que llegaran a ser grandes guerreros, debía ser entre los 18 y 20 años, siendo la edad de los hombres la que rondaría los 25 años. (41)

El matrimonio también era acordado entre el novio y el padre de la novia, quedando el matrimonio por rapto como una costumbre de la época arcaica. El sistema de propiedad en Esparta ha provocado un gran debate. Autores como McDowell y Hodkinson sostienen que para el siglo $\mathrm{V} \mathrm{aC}$, la mayoría de las tierras estaban en manos particulares.

Aristóteles justifica la debilidad de la sociedad espartana en la desigual distribución de las tierras, incluyendo el hecho de que dos quintas 
partes de las tierras estaban en manos de mujeres (42). Aristóteles nos ofrece dos causas: un gran número de herederas, sin restricciones de quién puede tomarlas en matrimonio y el hecho de que las dotes eran económicamente importantes.

Aunque las reglas sobre las dotes están lejos de aclararse, parece probable que una mujer espartana pudiera heredar parte del patrimonio paterno, incluso en presencia de hermanos. Probablemente recibirian la mitad de lo que le correspondiera a un varón como en Gortina. En el caso de que no hubiera hermanos, heredaria todas las propiedades o estaría obligada por su padre a casarse con el pariente más cercano(43).

En el siglo III a.C. el rey Agis IV llegó a incluir entre sus reformas que las ricas mujeres, como su propia madre y abuela, entregaran sus propiedades. No hay duda de que en la época de Aristóteles las mujeres espartanas gozaban de buena posición económica, quizás también como resultado de la disminución de hombres espartanos a finales del siglo $\vee$ y principios del IV a C. Para el siglo III aC, la mayor parte de la tierra estaba en poder de las mujeres (44) e incluso intrigaron contra Agis IV, porque sus leyes nuevas sobre redistribución de tierras les quitaba el poder que ahora tenían.

Según Hodkisnson, los derechos de propiedad de las mujeres debian estar asociados con cortos periodos de inestabilidad en los que la tierra cambiaba constantemente de manos al heredar las hijas tanto del padre como de la madre y las propiedades estaban destinadas a grandes divisiones a la muerte del padre. Para suavizar esto, se llevaron a cabo matrimonios entre parientes cercanos, así como algunos con edades muy avanzadas. Habría una concentración de la propiedad y un descenso en el número de ciudadanos espartanos. (45)

La ley espartana estipulaba que la principal misión de la mujer era criar hijos sanos por lo que se las educaba físicamente para que tuvieran cuerpos fuertes y bien predispuestos a la concepción.

La visión que nos llega acerca de las mujeres espartanas a través de las fuentes resulta paradójico. Estas mujeres eran independientes, poderosas y habladoras y podian ganarse una reputación de promiscuidad y de falta de control. Al mismo tiempo ellas ocupaban una parte importante en la sociedad espartana y fueron absorbidas por el aparato de control del estado para criar generaciones de guerreros. Como señala Hodkinson, durante la época arcaica y la clásica, habría idénticos propósitos entre el estado y la influencia de la mujer en el hogar. Pero en el siglo IV, este propósito del estado se debilita por el crecimiento económico de las mujeres. El resultado fue la falta de control por parte del estado y la liberalización de las mujeres. 


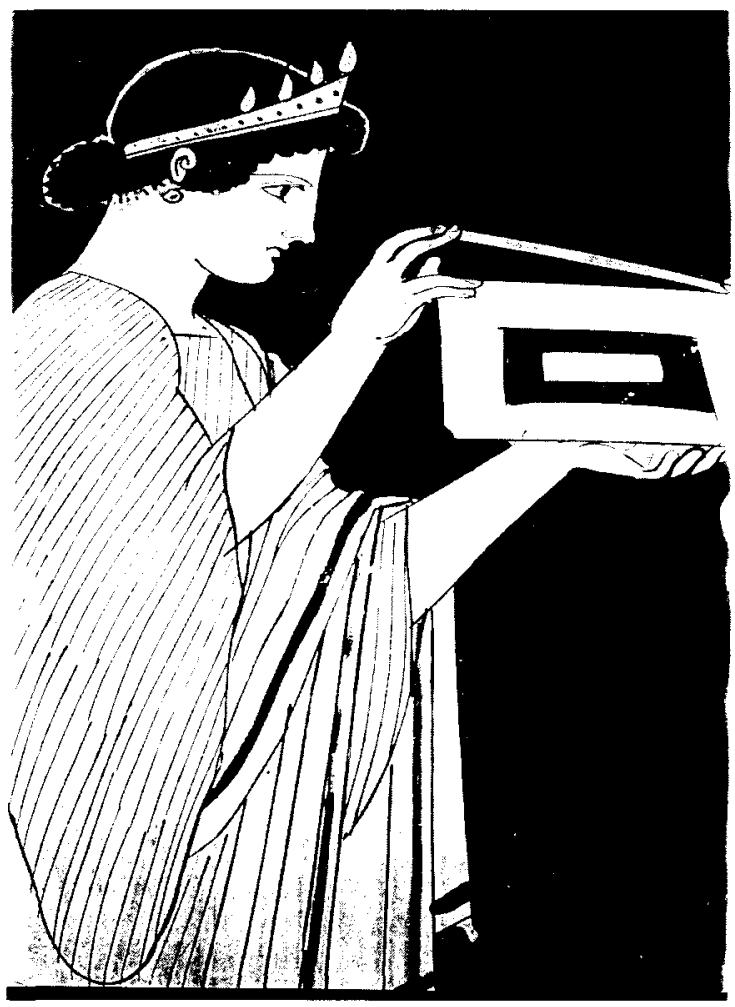

Fig. 7. Ánfora s. v a.C. Walters Art Gallery. Baltimore. El mundo femenino se nos antoja como algo misterioso aún para nosotros, como la mirada sostenida de esta jóven abriendo con cuidado una caja.

Cartledge añade que el papel encomendado a las mujeres espartanas de criar guerreros fuertes, ya situaba a la mujer en un estatus elevado en la sociedad espartana y le daba un control total en el hogar, sin olvidar que este sistema funciona gracias al sometimiento al que eran sometidos los hilotas. El sistema social espartano, quizás debido a sus propias contradicciones, estaba destinado al fracaso.

\section{MUJERES EN GORTINA}

Al igual que en Esparta el papel que debía desempeñar la mujer en Gortina era el de criar niños fuertes que se convirtieran en fuertes guerreros. A los 16 años los jóvenes eran enrolados en tropas, para entrena- 
miento militar y antes de ese momento, parece ser que ya vivían en comunidad con otros jóvenes.

Las dos grandes diferencias que podemos encontrar entre la mujer de Gortina y la ateniense son las siguientes:

- Una mujer en Gortina podia ser la legítima dueña de sus propiedades que le eran devueltas en caso de divorcio.

- El proceso de poder dentro del oikos aún no estaba tan desarrollado como en Atenas, por lo que los derechos de sucesión de las mujeres sobrevivieron como herencia de la estructura tribal que predominaba (46).

En Gortina la hija de un hombre sin hijos era denominada «patroiokos", (epiclera ateniense). Podía casarse a partir de los 12 años y tenía como primer objetivo tener herederos. Podía ser reclamada en matrimonio por sus tíos paternos y después por primos paternos en orden de edad.

Las leyes en Gortina parecen ser mucho más detalladas que las atenienses en concepto de matrimonio. Mientras en Atenas se presta especial atención a la obligación de casar a las herederas, en Gortina, existe una ley casi para cada eventualidad posible, tales como diferencias de estatus, edad, negarse al matrimonio, incluso el proceso llamado de "afairesis", que consistía en disolver el matrimonio de una esposa, al convertirse en heredera y ser reclamada por un pariente del difunto:

- " La heredera debe casarse con el hermano más viejo de su padre. Si hay más de una heredera y hermanos del padre, cada heredera se casará con el próximo hermano más viejo. Si no hay hermanos paternos y sí sus hijos, la heredera se casará con el hijo del hermano mayor. Si hay más herederas o hijos de hermanos, cada heredera se casará con el hijo del hermano de más edad (epibalion o pariente llamado a heredar cuando no hay hermanos, hermanas o hijos del fallecido). En caso de que la persona requerida para casarse con la heredera sea demasiado joven, si hay una casa, pertenecerá a ella y la mitad de las rentas provenientes de cualquier medio pertenecerán a la persona con la que se tiene que casar. Si la persona que debe casarse con la heredera no desea hacerlo, aunque ambos estén en edad de llevar a cabo el matrimonio, todas las propiedades y los ingresos pertenecerán a ella hasta que él se case con la heredera. Si el adulto epibalion no desea casarse con la heredera, mientras ella está en edad de hacerlo y además desea casarse con otra mujer, el kadestai (responsable de las herederas en casos de seducción o matrimonio) le llevará a juicio y el juez puede obligarle a casarse en el plazo de dos meses. Si aún así no se casa, ella se quedará con todas las propiedades y se casará con el próximo epibalion en el orden establecido, si es que exísten. Si no existieran, ella se casará con alguien de la tribu que ella elija y que él la pida en matrimonio. (47)

Las hijas también heredaban ya fueran tierras, dinero, etc. aunque su parte era la mitad de la que le correspondia a un varón. Lo único que no 
le estaba permitido heredar era el ganado y la casa. La mujer en Gortina heredaba del padre y de la madre, pero no existía la dote. Un padre podía hacer un regalo a su hija el día de su boda, pero sólo en los límites de su parte de la herencia, por lo que estos regalos eran un anticipo de su herencia.

En Gortina el esposo y la esposa compartían los ingresos de sus propiedades, pero la mujer tenía el control de sus tierras y el esposo no podía venderlas o hipotecarlas. Cuando el esposo moría, la viuda podía casarse de nuevo llevándose sus propiedades y todo aquello que el esposo le hubiese regalado. En caso de divorcio, tenía sus propiedades y solo la mitad de lo que producian esas propiedades, además de la mitad de lo que hubiera tejido. Cada parte podía iniciar el proceso de divorcio, y si se encontraba al marido culpable de adulterio, se le hacia pagar una pequeña cantidad de dinero como compensación a su esposa.

Adulterio y violación no eran públicas ofensas y eran compensadas con dinero. La cuantía de la sanción era igual para hombres que para mujeres, pero en caso de adulterio, la cantidad era el doble si el acto se hubiera llevado a cabo en el hogar del padre de la mujer, hermano o marido. No habia pena por adulterio entre un hombre libre y una esclava. De acuerdo con Eforo los hombres en Creta eran obligados a casarse cuando dejaban las tropas, pero no vivían con sus esposas. La referencia al adulterio en casa del padre de ella, puede indicar que la mujer vivía con su padre después de haberse casado. Según Éforo, la novia se iba a vivir a casa de su esposo cuando éste podía ya dirigir un oikos.

En un sistema como el de Gortina, en el que las propiedades de los cónyuges permanecían separadas como entidades distintas, la muerte de uno de ellos solía ser causa de disputas. La esposa retendrá lo que llevó al matrimonio además de todo aquello que su esposo le regaló durante el matrimonio. En caso de que sea ella la que muera, el esposo devolverá a los parientes de la difunta las propiedades junto con la mitad del ajuar, sus vestidos, y la mitad de lo obtenido en las propiedades agrícolas, si dichos productos provienen de las tierras de la difunta.

Si el esposo muere dejando hijos, la esposa puede casarse de nuevo guardando su propiedad y cualquier cosa que su esposo le haya regalado en presencia de tres testigos adultos, según lo marcado por la ley. Si ella coge cualquier cosa que pertenezca a los hijos puede ser perseguida por la ley.

Si el esposo muere sin dejar descendencia, ella guardará su propiedad, la mitad del ajuar y tomará su porción del producto familiar, junto al epibalion.

Si la que muere es la esposa, el esposo devolverá la propiedad. 
Era algo muy común que existieran reclamaciones en caso de divorcio, alegando unos que la esposa se llevaba más de lo que le correspondía por ley. En estos casos, un juramento de la esposa era suficiente para probar que solo se llevaba lo que legalmente le correspondia.

En el caso de que la esposa se llevara algo de más, pagaba una multa de 5 estéteras, además de devolver aquello que no le correspondía. Si se negara a pagar esta sanción, jurará ante Artemis en el Amiklaion, que ella no se ha llevado más de lo que le correspondia. Si un extranjero le ha ayudado a llevarse cosas, pagará el extranjero 10 estéteras y el doble del valor de lo que ha ayudado a llevarse.

Como podemos comprobar, la legislación en Gortina era muy minuciosa y podía cubrir la mayoría de las situaciones que pudieran darse a lo largo de un matrimonio, una disputa por una herencia o un caso de divorcio.

\section{CONCLUSIONES}

Los griegos habian llegado en sucesivas olas de invasión durante un periodo de varios cientos de años. Aunque cada grupo tenía distintas caracteristicas, su lenguaje, cultura y comportamientos, tenian bases comunes.

Las leyes sin embargo, fueron formuladas en los estados griegos sólo después que se separaran en poleis independientes y entonces cada ciudad formuló su propia ley, basada en la preexistente cultura : monogamia, herencia por proximidad de pariente con varones precedente a mujeres y la estructura de tribus, clanes, oikos, kirios, etc. reaparecieron por toda Grecia en cada uno de los sistemas legales conocidos.

Pero la ley no es sólo un reflejo de la sociedad que la produce. La misma institución puede ser desarrollada en diferentes formas según el lugar. La herencia por ejemplo, puede ser una mera forma de reciclaje de los bienes del muerto, o de regular el liderazgo de su casa cuando el líder muere o de llevar a cabo los deseos del difunto e incluso de garantizar la supervivencia del núcleo familiar. En cualquier caso, se adopte el sistema que se adopte, el trasfondo será el mismo.

En Esparta y Gortina encontramos dos sociedades en las que la mujer asume un papel mucho más importante que en la sociedad ateniense, llegando a ser la legitima dueña de sus propiedades. En Atenas por el contrario, los atenienses reconocian a sus mujeres como personas, y estaban interesados en su bienestar, pero no confiarian a una mujer las propiedades que garantizaran ese bienestar. La protección a la mujer se expresaba no a 
través de derechos directos para ellas, sino a través de un sistema de obligaciones para el hombre. No se conoce mejor definición de paternalismo.

\section{BIBLIOGRAFIA}

(1) Aristóteles. "Política", 1278 a.1.

(2) Harrison. "Greek laws". 1968.

(3) Janssens-Kuenen. Pág. 194. 1941.

(4) Sue Blundell. «Women in Ancient Greece», 1995.

(5) Demóstenes. 59.46.

(6) Heródoto. 3.50 .

(7) Heródoto. 5.92 .

(8) Dyskilos 842-4. Perikeizomene 1013-15.

(9) Harrison. "Greek laws". 21.4 (1968).

(10) Wolff. «Realencyclopadie der Klassischen Altertumswissenschaft».

(11) Epitrepontes. 1063-7.

(12) Menandri Reliquiae Selectae. Oxford University Press. 1972.

(13) Plutarco. 13.i.

(14) Eurípides. «Phacton». Edic. James Diggle. Cambridge. 1970.

(15) Demóstenes. 59.87.

(16) Aristófanes. "Nubes". 1083.

(17) Plutarco. «Alcibiades» 8.5 .

(18) Traducción de H. Lloyd Iones. "Lefkowitz and Font». 1982. Pág. 19-20.

(19) Isaeo 29 / 3.35-6. Demóstenes 59.52.

(20) Isaeo 3.36. Demóstenes 40.14/40.50.

(21) Isaeo 3.8-9/3.78.

(22) H.L.Levy "Mediterranean Countrymen». Edit. J. Pitt-Rivers. 1963. Pág. 142.

(23) Demóstenes 27.5/45.28.

(24) Isaeo 8.35.

(25) W. Dittenberg. “Sylloge Inscriptionum Graecarum». Leipzig. 1924.

(26) Lisias. 19.59.

(27) Demóstenes. 36.11/48.12-13.

(28) Roger Just. "Women in Athenian law and life". Pág. 86. London. 1989.

(29) Pilar Fernández Uriel. «El Mundo Griego». H. ${ }^{a}$ Antigua Universal II. UNED. Madrid. 1996.

(30) H. Adkinson. CQ 25. 1975. Pág. 217-218.

(31) McDowell. "Mnamosyne». 1963. 131-3.

(32) Plutarco. «Solón». 20. 2-5.

(33) Isaeo 6. 47. Demóstenes 43.51.

(34) Flaceliere. 1965.

(35) Finley M.J. “The use and abuse of history". 1975. Pág. 166

(36) J. Redfield. CJ 197. "The women of Sparta".

(37) Jenofonte. “Constitución» 1.4/ Plutarco. «Licurgo» 14.2.

(38) Plutarco. "Vida de Agesilao". 19.5.

(39) Platón. "Protágoras», 324 d.

(40) Plutarco. "Licurgo". 18.4.

(41) Paul Cartledge. CQ 31. 1982. "Spartan wives : liberation or licence?. Págs. 84-105."

(42) Aristóteles. "Política" 1270. a.

(43) Heródoto. 6.75.4.

(44) Plutarco. "Agis» 7.4.5.

(45) S. Hodkinson. "Inheritance, marriage and demography: perspectives upon sucess and decline of classical Sparta.»1989.

(46) Willets. "The law - code in Gortyn". 1967.

(47) Willets. "Ancient Creta". 1967. 